\title{
Using different art forms to investigate the impact on children's involvement in literacy activities
}

Evgenia Theodotou

Cass School of Education and Communities, University of East London, UK

University of East London, Cass School of Education and Communities, University of East London, Stratford Campus, Water Lane, London E15 4LZ, Tel: +44 (0)20 82234787

\section{e.theodotou@uel.ac.uk}

\section{Information about the author}

Dr Evgenia Theodotou is a Senior Lecturer in Early Childhood Studies and the program leader for BA (Hons) Early Childhood with Psychology program at Cass School of Education and Communities at University of East London. She is the external examiner of Staffordshire University at the Early Childhood Studies program, an external examiner for Open University at the Early Childhood collaborative programs and a Senior Fellow of The Higher Education Academy. She holds a $1^{\text {st }}$ class Diploma in Infant and Child Care Assistant from Sivitanidios College, a $1^{\text {st }}$ class BA in Early Childhood Education and Care from University (TEI) of Athens, a MA in Education from Durham University, a MSc in Teaching Technology and Digital Systems from University of Piraeus with Distinction and a $\mathrm{PhD}$ in Early Childhood Education with Distinction from the National and Kapodistrian University of Athens in the research area of "Literacy skills in the early years settings". She has more than 10 years of professional experience as a head teacher in the Early Years Settings and more than 8 years in Higher Education as a Lecturer/Visiting Lecturer in Early Childhood Studies. She has been for 4 years the Program Leader in Education Department in Metropolitan College. Her research activity is focused on literacy, the arts, creativity and technology enhanced learning. She has participated in several research projects and published her research in International Conferences, Journals, edited books and monographs. She is the author of "When I play I learn ... and I better understand" from Delta publications and of "Creativity in the era of New Technologies" from Kritiki publications. She has been a member in several Scientific Review Committees and organized several special sessions in International Conferences. 
University webpage: https://www.uel.ac.uk/Staff/t/evgenia-theodotou

Linkedin profile: https://gr.linkedin.com/pub/evgenia-theodotou/17/965/76

\section{Acknowledgements}

I am very grateful to the practitioners of the schools who agreed to participate in this study and gave their time and effort to this intervention. I would like to thank the parents who gave their permission to include their children in this research project. Special thanks to all the children who participated. It was a pleasure to work with you all. The research did not receive any specific grant from funding agencies in the public, commercial or not-for-profits sectors. 


\section{Using different art forms to investigate the impact on children's involvement in literacy activities}

Much of the research into factors that affect children's school performance has focused on parental involvement rather than the nature of children's activities undertaken in school. More research is therefore needed to examine the kinds of activities that affect performance and, in particular, whether the degree of involvement children experience in those activities can affect school performance. Children in free play often choose to be involved in arts activities so the arts could be considered as a promising approach. The purpose of this paper is to investigate the effects of 'Play and Learn through the Arts' program on children's involvement during literacy activities in five-six-year-old children. It was examined if the arts in general or a specific art form could contribute more to children's involvement in literacy activities. Children from four different settings participated in this study. To measure the outcome of the intervention the LIS-YC was used and items such as children's concentration, persistence and precision were measured. The findings were analyzed using a mixed method approach and showed significant benefits in all the items in children's levels of involvement in the arts group over the control group and no difference in effects among the different art forms.

\section{Keywords}

Involvement; Play and Learn through the Arts; Early Years Education; Arts; Preschool

\section{Introduction}

Activities in early years settings are important for children's school performance in the

future. At this stage of education, children build knowledge and develop skills that are necessary in their following years of schooling (Tymms et al. 2009; Siraj-Blatchford et al. 2008). The level of children's involvement in school activities in the early years is fundamental and is likely to promote their school involvement in the future as well. Therefore, it is crucial to find ways to trigger children's interest and motivate them in the teaching and learning process from a very early age.

Considering the different areas of learning, it can be argued that literacy is the most important one, as it is strongly related with all the other learning areas. One main argument for this aspect is that every learning area has its own communication code that is based on the basic principles of literacy. In addition, it is essential to consider children's voices in the design of literacy activities (Wray and Medwell 2006; David and Goouch 2001) and make space for 
multimodal opportunities in literacy activities (Loerts and Heydon 2017) as this will increase their level of involvement. Thus, it is considered of great importance to find a meaningful practice in literacy activities that will increase children's involvement. The arts are a very promising approach that provides opportunities for multimodal ways of communication and can be utilized in an interdisciplinary research project with literacy to increase children's involvement. The reason lies in the fact that the arts create an open-ended environment in which everyone has the opportunity to express themselves without being judged on the outcome (Vasudevan 2014; Matthews 2008). For example, a finished painting can be formed using a painter's imagination and way of expressing themselves. There is a less sense of being a right or wrong outcome. The benefits of this interdisciplinary approach are based on the argument that art activities are the predominant choice of children during their free play (Hanley et al. 2009).

The benefits of the arts on children's involvement are supported theoretically by many researchers (see Leavy 2015; Eckhoff 2013; Fleming 2008). Nevertheless, there is a need for more empirical research with such focus on the early years. More specifically, literature review shows that researches into the early years are mainly focused on parental engagement (see Wilder 2017; Tekin 2016; Giallo et al. 2013; Ishii-Kuntz 2013) which is a crucial factor in children's learning too. However, following Siraj-Blatchford's et al. (2008) arguments, the examination of children's involvement during school hours is also a key area for research. Preliminary results of some pilot studies in previous pieces of research (see Theodotou 2017a, 2017b, 2017c; 2015) show that in small-scale studies, an art intervention had beneficial outcomes on children's social, productive and receptive skills, as well as on the level of their involvement during literacy activities.

This paper is based on the above arguments in an effort to provide empirical evidence on a larger scale and to compare the outcomes against a control group. The purpose of this study is to investigate the effects of 'Play and Learn through the Arts' (PLA) program on children's involvement during literacy activities. PLA was introduced as a teaching approach (see Theodotou 2017a, 2015) to support children's achievements in literacy in the early years settings through child-led art activities. It is not a commercialized program and thus it can be utilized without any financial expenditure to third parties. In this study, PLA was used to enhance children's involvement in literacy activities. It was further examined if the arts in general or a specific art 
form such as paintings, drama and puppetry could contribute more to children's involvement during literacy activities.

\section{The arts as a promising teaching approach}

Providing a definition for the arts using conventional formats is difficult, given that they include so many different ways of meaning making. They offer the opportunity for free communication and expression of ideas and allow people to go beyond the ordinary (Matthews 2008). They have their own communication system, which does not follow any kind of traditional and typical rules. According to Vasudevan (2014), when people are involved in art activities, there is an effective communication among them, sharing their thoughts and ideas. One of the main reasons is that while utilizing art resources, people have the opportunity to express themselves without following any kind of strict or specific rules in their communication and interactions. Hence, people are able to use any type of communication mode they feel more comfortable with, in order to share their thoughts with the others.

Art-based research has been around for some years now and it offers detail-rich information, comparing to the typical research methods, as participants can transform their reality (Leavy 2015). This is based on the fact that, through art experiences, people feel free to reveal their true emotions and thoughts as they are acting in an open-ended framework where they don't feel that they will be judged. The benefits of the arts in the education field about creativity have attracted researchers' attention for some time now (see Yu et al. 2017; Isenberg and Jalongo 2014). Although this is a very important aspect, there are researchers who argue that the arts can offer many more benefits than just creativity (Fleming 2008; Eisner 1973-1974). Wright (2007) established a strong link between the arts and children's communication in the early years settings by describing how young children communicate their ideas with their first efforts of drawing. She highlighted that children, who engage in graphic-narrative play, display high communication skills, by adopting different roles, such as author, scripter or narrator. Some years later, Maniaci and Olcott (2010) agreed with these arguments by stressing the communicative character of the arts. They made arguments about the importance of art activities in developing school knowledge, especially literacy skills.

It should be remembered that the true purpose of the arts is to communicate ideas and not to be utilized as an educational tool. However, the open-ended character of the arts can trigger 
students' attention, which could be used beneficially in the learning activities because children would be more interested to participate. This argument is based on the fact, that in the early years settings, children have an innate tendency to use art activities in their free play time (Hanley et al. 2009). Therefore, using the arts as a means could result in achieving better cognitive and social performance as children could be more involved, which will ease the digestion of new knowledge and understanding of key topics.

Considering the above arguments about the importance and the benefits of the arts, it seems that there is a need to find ways to involve the arts more often in the learning activities of young children. This will result in higher levels of involvement in school activities, as children will get used to interacting in a less constrained environment. However, it is important to verify these arguments through an empirical study and compare the outcomes against a control group.

\section{Relevant research about involvement and art involvement}

Involvement is a crucial part of people's activity as it provides evidence of their concentration and correspondence during a specific task. When someone is involved deeply in an activity, it is very rare that they will be distracted before its successful completion. According to Laevers (1994), involvement is an aspect of people's actions, which is characterized by motivation, persistence and amusement. He also highlights that involvement is obvious in people's activities that are derived by internal motives and not initiated or suggested by external motives.

In the research field, there is an over-emphasis in the examination of engagement and more specifically parenteral engagement in contrast to children's involvement in learning activities in the early years settings. It has to be acknowledged that there is a difference between the terms involvement and engagement. Involvement indicates an action in something, whereas engagement indicates an action with someone (Ferlazzo 2011). For example, a child will get involved in an arts activity but will engage with their parents to do their homework. Parental engagement has also a positive effect on children's learning but as Siraj-Blatchford et al. (2008) identified, it is even more important to examine children's involvement during school activities.

Reviewing the existing empirical literature, researchers investigate children's involvement in relation to teaching strategies. Ridley et al. (2010) are some of the researchers who investigate this aspect in the early years settings. They focused their research on three-year-old children in 58 
classrooms. The researchers linked the quality of school activities with children's involvement and examined children's interactions with the practitioners. They implemented a meticulous sampling method, managing to have similar group size in the different classrooms and similar staff qualifications. This was a major strength in their research, as it resulted in reducing upcoming influencing effects in their data that might have derived from differences among the participants. Data collection followed a very robust procedure, but clearer arguments were needed regarding the pedagogical framework they embraced. However, it is obvious that the researchers are in favor of the social construction of learning as they focused on group interactions.

A couple of years later, Phelps et al. (2012) investigated the aspect of teaching interactions and involvement in a higher level of education in more depth, adopting a different focus. They examined 46 nine-ten-year-old children to find the ways teachers' strategies affect children's levels of involvement. The researchers focused their methods on interviewing the students. This was a very clever approach as they gained data from the direct recipients of the teaching process. The researchers concluded that there are high levels of involvement when teachers use a variety of teaching strategies and focus less on direct instruction. These findings are very important for practitioners' self-improvement as they raise the issue of diversifying the teaching practices to support students' performance.

The aspect of literacy involvement in the early years was investigated by Baroody and Diamond (2012) but with no direct focus on the arts. The researchers included 167 four-five-yearold children to examine their interests and involvement in literacy activities. The researchers used a variety of methods like children observation and interviews of parents, teachers and children. The variety of methods was an asset in their methodology as they enriched their data and examined this aspect from different perspectives in order to gain a holistic view. The findings showed a significant effect on children's interest in literacy and their involvement and this was common in all the different methods they used.

Researchers into mainly the higher levels of education provide a more specific focus on the effects of the arts on students' involvement. The study of Gerry et al. (2012) is one of the very limited pieces of research that focuses on the early years settings but not in literacy activities. The researchers were keen on investigating the effects of music on infants' involvement and social development. Their sample consisted of 49 six-month-old infants with their parents. They 
categorized their sample in experimental and control groups. The former group had active participation during musical experiences, which meant that parents and infants followed the Suzuki-philosophy which entails movements, singing and playing instruments. The latter had a passive participation, which meant that parents and infants just listened to music. The researchers concluded that active involvement in music activities had better outcomes in infants' social development compared to the control group.

The part of academic and cognitive development that was missing from Gerry's et al. (2012) research was covered by Garvis and Klopper (2014) who included the early years settings in their methodology. Garvis and Klopper (2014) investigated four different case studies of formal and informal schooling, although only one of them was in early years settings, as they mainly focused on secondary and higher education. The researchers concluded on the importance of art experiences in children involvement, which resulted in effective learning outcomes.

Summarizing the above discussion, researchers are very interested about the importance of children's active and deep involvement in learning activities and the benefits of the arts in this process. Although, there are pieces of research that investigate the importance of active involvement in the early years settings, there is a need for more research that includes the contribution of the arts and focus on literacy activities in the early years settings. As it is mentioned earlier, literacy is the most important learning area in children's development as it establishes the basic communication code for the rest of the learning areas. Considering the importance of literacy and the benefits of the arts, it is importance to examine and find meaningful ways that we can use the arts to promote children's involvement in literacy activities. Based on these thoughts the following research project was designed and implemented.

\section{Purpose}

The literature review shows that there is a need for more research that examines children's involvement during school activities, especially in the early years, using an interdisciplinary approach with the arts. This argument and the findings of small-scale pieces of research with such a focus (see Theodotou 2017a, 2017b, 2017c, 2015) were the motivating factors for this piece of research. The purpose of this paper is to investigate the effects of 'Play and Learn through the Arts' (PLA) program on children's involvement during literacy activities. It was further examined 
if the arts in general or a specific art form such as paintings, drama and puppetry could contribute more than others, in children's involvement during literacy activities.

\section{Research questions}

The research questions that this piece of research is trying to answer are the following:

1. What are the effects on children's involvement during literacy activities when they are interacting with the arts?

2. Does a specific art form have a stronger effect on children's involvement during literacy activities?

\section{Participants}

The participants of this study were from four different early years settings, from both state and private sector in Attica in Greece, with children in the age group of 5-6 years old. The settings were selected using a probability sampling technique of simple random sampling. A list was created with all the settings in Attica and there was a random selection of 20 of them. After faceto-face meetings with the staff of each setting, the four settings that agreed to participate formed the sample of this study.

From these four settings, three of them were allocated to the experimental groups and one of them to the control group. This was based on the practitioners' preferences. In total, there were 61 children, with 18 children in experimental group 1 (EG1), 15 children in experimental group 2 (EG2), 14 children in experimental group 3 (EG3) and 14 children in the control group (CG) (see table 1).

[Insert table 1]

\section{Procedures}

The intervention was implemented by the practitioners in each setting during school hours, as it was considered beneficial for the children to interact in their familiar surroundings. The experimental groups implemented the 'Play and Learn through the Arts' (PLA) program for one school year. Each group selected one art form of the following: paintings, drama and puppetry to use for this project during the PLA (see table 2). The control group implemented the mainstream guidelines from the Greek early years curriculum. 
[Insert table 2]

The three experimental groups implemented the steps of PLA alongside with the existing practices. There was a suggested time schedule of three times per week for 20-30 minutes per time, but each group had the freedom to adjust this according to the needs and interests of the children. Regarding the support to the practitioners, there was an induction period before the intervention with the goal to offer the practitioners the opportunity to familiarize themselves with the procedure. During the intervention, there were several consultation meetings to discuss any matters arising and discuss children's progress. To reduce any influencing factors in the control group, during the daily program there were art activities provided by an art teacher focusing on different drawing techniques e.g. pointillism, following templates and symmetry, using sponges, straws or stamps.

\section{The 'Play and Learn through the Arts' (PLA) program}

PLA is an interdisciplinary program that was designed to support children in the development of literacy skills in the early years settings through art activities. It was implemented in some pilot studies with a small-scale sample (see Theodotou 2017a, 2017b, 2017c, 2015) with very positive outcomes. Based on these findings, this study used the PLA in a larger scale sample to verify its benefits and test if the arts in general or a specific art form would contribute more in children's involvement.

PLA embraces the social construction of learning and the fact that literacy is an undivided learning area instead of fragmented skills, such as receptive language skills, productive language skills, reading comprehension, phonological awareness skills etc. Students and practitioners use an art form of their choice to begin literacy activities. The difference from other art interventions is that PLA encourages children to use the arts for developing literacy activities instead of doing art activities and literacy activities in parallel. In addition, children and the practitioner have very active roles and there are no ready-made art lesson plans or activities. The basic reason for this is that PLA wants to empower children to have an active role in their learning.

There are 5 basic steps (see table 3 ) that are suggested. Children should collaborate in every step of the PLA and the practitioner acts as a facilitator of the whole process. The different steps of the program are not linked directly to a specific art form and participants have the freedom to 
select the art form they are more interested in. The following five steps are suggested on a weekly/monthly basis:

[Insert table 3]

\section{Measures}

To answer the research questions, the Leuven Involvement Scale for Young Children (LISYC) was used. This measure was developed by Laevers (see Laevers 1994) to examine children's involvement during learning activities. It provides qualitative and quantitative data that is based on observations, examining children's levels of involvement holistically. Reliability of the quantitative part of LIS-YC was measured using Cronbach's alpha. The analysis showed that all items had a good level of internal consistency as the result was above 0.8 (see table 4).

[Insert table 4]

This measure was used twice, once in January and once February, at the middle of the intervention, at the same period in all experimental and control groups.

\section{Data analysis}

The collected data regarding children's involvement was first tested against children's demographics to examine if there were any influencing factors that might have affected the findings. Kolmogorov Smirnov test showed that LIS-YC did not have a normal distribution $(\mathrm{p}=.000)$ (see table 5) and therefore Mann-Whitney U test was used for the values 'gender', 'place

of birth', 'nationality' and 'multilingual' as they are binary values. Kruskal-Wallis $\mathrm{H}$ test was used for the values 'order of birth' and 'family status' as they are nominal with more than two values. Spearman test was used for the value 'siblings' as it was a scale value with no normal distribution $(\mathrm{p}=.000)$ (see table 6$)$.

[Insert table 5]

[Insert table 6]

Data analysis showed that demographics had no effect on children's levels of involvement, which was very positive. There was no statistical difference $(p>0.05)$ in the numbers in all nine 
signals of LIS-YC, which means that demographics did not influence children's performance (see table 7).

[Insert table 7]

Following this, further analysis was conducted regarding children's involvement among the different groups for the quantitative part of the LIS-YC. Fisher's Exact test was used as the conditions of the Chi-square test were not satisfied. To answer the first research question 'What are the effects on children's involvement during literacy activities when they are interacting with the arts?' there was a comparison of the data among the experimental and control groups. The data analysis showed that there was an effect on children's performance when interacting with the arts during the PLA as there was a statistically significant relationship $(\mathrm{p}=.000)$ in all 9 signals of LISYC, comparing the control group with each one of the experimental groups (see table 8). Analyzing the data further into the five levels of involvement, it is obvious that during the PLA, children had higher levels of involvement in literacy activities comparing with children in the control group. In a five-point Likert scale with Level 1 being the lowest and Level 5 being the highest, the numbers in the experimental groups were gathered mainly in Level 4 and Level 5 and there were some limited entries in Level 3. On the contrary, the numbers in the control group were gather mainly in Level 1, 2 and 3 (see table 9).

[Insert table 8]

[Insert table 9]

To answer the second research question 'Does a specific art form has a stronger effect on children's involvement during literacy activities?' a further examination was conducted among the different experimental groups. Data analysis showed that there is no different effect on children's performance, as there is no statistically significant relationship $(\mathrm{p}>0.05)$ in all nine signals of LISYC among the different experimental groups (see table 10).

[Insert table 10]

To provide further evidence regarding the intervention, the data was further analyzed with a qualitative approach by debriefing the observation notes of LIS-YC. Through this analysis, it was further verified that children in the experimental groups had higher levels of involvement in 
literacy activities compared to the children in the control group. In addition, there was no evidence that a specific art form had a better contribution to children's levels of involvement and it is obvious that the arts in general had a positive outcome.

A basic signal of involvement is concentration. According to Laevers (1994), concentration reveals people's attention and focus towards an activity. It is highly unlikely for someone who is totally concentrated to be distracted by external or internal stimuli that are irrelevant to the activity. Concentration is also the major reason for completing successfully an activity and gaining deeper understanding (Siraj-Blatchford et al. 2002). The data from this study is linked with these arguments, as children in the experimental groups were totally concentrated in literacy activities when they were interacting with the arts and PLA was implemented. This could be illuminated with the following extracts from the data:

EG1, Child 7: Her attention is totally directed towards the whole procedure and nothing can distract her to reach her goals. She does not pay attention to other children and irrelevant stimuli or distractions do not affect her. She is waiting patiently for her turn to describe the painting or go to the writing table to write a letter to the painter.

EG3, Child 6: He is watching very carefully the puppet play and is very concentrated during the literacy activity. Nothing can distract him from the activity although sometimes his friends accidently poke him. He is participating in the puppet play and suggests solutions to the upcoming problems that the puppets might experience.

On the contrary, children in the control group were mostly related with lower levels of concentration and they were easily distracted during literacy activities. An extract from the data to illuminate this argument is as follows:

CG, Child 1: He is in constant move and does not pay attention to the teacher or the activity. He is looking at the furniture of the classroom and his classmates. His attention is directed to other things and not to the activity he is doing. He tries to imitate his friends in order to finish the activity and play with other things. 
$C G$, Child 2: She is concentrated only during the introduction of the activity and the discussion but other things frequently interrupt her concentration. She is looking sometimes at her surroundings or she is staring at her shoes.

Non-verbal attitude is also another important signal of students' involvement in an activity and it is very important in making judgements about the level of someone's involvement. Nonverbal communication is usually characterized as the truthful way of conveying messages (Tonc 2002). This is based on the argument that it is extremely difficult not to disclose these messages through facial expression, responses, gestures etc. The evidence from the data analysis is associated with these arguments, as positive signs of nonverbal attitude are obvious in all the experimental groups. During the arts activities in the PLA, students revealed high levels of involvement in literacy activities through their non-verbal attitude. This could be illuminated with the following extracts from the data:

EG1, Child 7: Her body posture shows that she cannot be more involved in the whole procedure. She has intense eyes constantly, which reveal deep thinking of her next step. Her body posture shows that she is deeply concentrated. She put the pencil in her mouth when she wants to think.

EG2, Child 9: Nonverbal signs show deep concentration during the whole procedure. She tries to think the next phoneme she wants to write for her drama play about space and planets. She closes her eyes and put her fingers in her mouth. She has intense eyes during the literacy activity that reveal her deep thinking.

When PLA was not implemented as a motivating factor for literacy activities, the levels of children's involvement were not so high. The data analysis showed that children in the control group revealed lower levels of involvement in this area, revealing neutral or negative non-verbal signs. Some extracts from the data are as follows:

CG, Child 6: Her nonverbal posture shows boredom and a passive attitude. She has dreamy eyes during most of the time of the activity and discussion.

CG, Child 9: Her nonverbal signals and attitude are mostly vague as something else preoccupies her and not by the activity itself. 
Another important factor for making judgements for the levels of someone's involvement is the level of persistence and precision during an activity. Persistence is highly linked with academic performance and involvement and it is mainly influenced upon the first impression of the students (Cai 2014). High levels of participation are mainly attributed on children's persistence in completing an activity (Burdette et al. 2015). Persistence in fulfilling an activity will result in precision during the whole process. When children insist to reach their goals, they are also very precise in doing every step right, avoiding mistakes and paying attention to details (Laevers 1994). The data analysis verifies the above arguments. Children from all the experimental groups showed high levels of both persistence and precision during literacy activities. Most of the children were very attentive to details and did not let go the activity easily when they experienced difficulties until they reached their goal. This could be illuminated with the following extracts from the data:

EG1, Child 9: She insists to reach her goal. She does not let go easily and tries to write as many words as she can for the little Picasso. She asks for permission to write whatever she wants and starts writing pseudo letters and words. She is going to another table and waits to get the color she wants. She is very attentive to details. She is trying to do very small letters and she paints very lightly the four corners of her paper. She makes a mistake at the beginning and she turns over her paper to start again. She uses the back of her paper to test first the marker.

EG3, Child 11: She wants to write a letter to the puppets about their new puppet play. She put effort in order to achieve her goal and she tries to utilize the hints that are provided by her surroundings (e.g. name tags, books, word wall etc.). She does not let go easily. She is trying to find ways to improve her outcome and to prolong the activity (e.g. she is discussing with her classmates what else they could do). She is looking very carefully her outcome to find what she forgot to do. She adds the parts that she thinks are important and selects very carefully the color of the marker.

On the contrary, children in the control group revealed a very different attitude during literacy activities where there was no art intervention. The level of children's persistence and precision was often lower during the whole activity and there were incidents that they were careless and did not worry about the outcome. Some extracts from the data are as follows: 
CG, Child 3: He does not persist to fulfill his goal but he states that he wants to finish. His handwriting is not careful and he does not care if he makes some mistakes. He is careful to follow the guidelines but he is not so careful with the details of the activity. $C G, C h i l d 4:$ There is no persistence in the activity by his side. When he realizes that he has to do something that needs effort, he tries to copy the outcome of his classmates. He is very careful when he is copying the words from his friends but this is frequently interrupted by irrelevant conversations that distract him from his final goal.

To briefly summarize, the above data from LIS-YC shows that the arts, and more specifically the PLA, have a beneficial effect on the levels of children's involvement during literacy activities. Quantitative analysis verifies that there is a positive outcome when the arts are used to trigger literacy activities. Evidence from the data analysis shows that there is a significant effect on all items of LIS-YC among the control group and all the experimental groups, with a significant difference. Therefore, the answer to the first research question is that the arts contribute positively to children's involvement in literacy activities. In addition to this, there was no different effect on children's involvement in all the items among all three experimental groups, which provides evidence for the second research question regarding the effects of the different art forms. More specifically, the answer to the second research question is that the arts in general contribute beneficially to children's levels of involvement with no particular stronger impact of one art form over the other ones.

The positive effect of the arts is obvious from descriptive statistics, in which children in the control group were frequently distracted during the literacy activities. In comparison, children in all three experimental groups were involved deeply in the literacy activities. Qualitative analysis of LIS-YC supports this argument and enriches the existing quantitative data. During this analysis, a detailed and descriptive record was provided, which verified the positive contribution of the arts in children's involvement in literacy activities comparing with the control group. Therefore, it can be argued that children who did not use the arts to initiate literacy activities were less involved comparing to children who utilized the arts and more specifically the PLA.

\section{Discussion}

Reviewing the existing empirical literature about the arts and children's involvement, it is obvious that there is a need for more research that focuses on the contribution of the arts in 
children's involvement and especially in literacy activities. There are many arguments that the arts contribute positively to children's involvement in learning activities but these arguments are mainly focused on primary or secondary education. The findings of this study shed light on this by providing empirical evidence that has been tested against experimental and control groups.

Examining these arguments, we can conclude that the arts are among the most common activities chosen during children's free play. This practice results in great levels of involvement as it is based on children's true needs and desires. According to Fleming (2008), drama play is strongly related with motivation, which results in deep involvement in the relevant activities. This argument agrees with the findings of this study as it supports the benefits of the arts in children's involvement. The findings of this study enrich this argument in multiple ways as the data focuses on the early years settings, focuses on literacy activities and provides empirical evidence.

Catterall et al. (2012) investigated four different longitudinal studies and concluded that art interactions have a positive contribution in at-risk teenagers and young adults. In their study, there are indirect arguments about the effects of the arts on students' involvement in the activities. A couple of years later, Garvis and Klopper (2014) confirmed this and provided direct arguments about the effects of the arts on students' involvement in learning activities. By investigating four case studies of formal and informal schooling, they highlighted that art experiences are responsible for higher levels of students' involvement and contribute in the development of students' empathy. One year later, Nichols (2015) also verifies this argument in high school students. She confirmed clearly that the arts have a substantial contribution in students' involvement in school activities and have the opportunity to sustain their interest for a long time.

The findings from the above pieces of research agree with the findings of this study. They all verify the beneficial impact of the arts in children's involvement in learning activities through an experimental design in the later levels of education. However, what is missing from the previous empirical evidence is a direct focus in the early years settings, which is provided by our study.

Finally, yet importantly, Rydzik et al. (2013) provide empirical evidence about this argument with an indirect focus on the wider concept of literacy. They focused their study on measuring the levels of involvement during art activities in adult students and concluded that arts experiences result in better verbal and non-verbal expression. Comparing these findings with the data of this study, it is obvious that there are substantial links and similarities among them, 
regarding the benefits of the arts in students' involvement in activities. However, our study supplements these findings as it provides more specific evidence in the early years settings and in literacy activities.

Overall, the findings of this piece of research contribute to this discussion and offer empirical evidence in the early years settings that there is a need for more research about the effects of the arts on children's involvement in learning activities. To answer the research questions of this study, the arts have a very positive impact in children's involvement during literacy activities in the early years settings and there is no specific art form that has a better contribution comparing with the other ones. The findings of this study support the existing empirical literature and enrich it by offering additional evidence in the early years settings and by focusing on literacy activities that is something that was missing from the previous pieces of research.

\section{Conclusions}

This research project focused on the early years settings and, more specifically, on the effects of the arts on children's involvement during literacy activities. During the review of the literature, it was obvious that there are theoretical or indirect arguments about the positive impact of the arts on children's involvement at school activities but when we limit our search to the literacy activities in the early years settings, it is getting even more difficult to find relevant pieces of research. The findings of some small-scale pieces of research with such a focus (see Theodotou 2017a, 2017b, 2017c, 2015) were very positive and thus, this research project was designed. More specifically, the purpose of this study was to investigate the effects of the PLA on children's involvement during literacy activities. It was further examined if the arts in general or a specific art form such as paintings, drama and puppetry could contribute more to children's involvement during literacy activities.

There was an examination among three experimental groups and a control group using a mixed method approach. The findings were very positive and confirmed the beneficial contribution of the arts in children's involvement in literacy activities. However, there was no evidence that a specific art form has a better contribution compared to the other ones. Therefore, this leads us to suggest that it is the arts in general that have a positive contribution to children's involvement in literacy activities and not a specific art form. The findings of this study agree with the existing 
empirical and theoretical literature and enrich it by focusing on literacy activities in the early years settings, which is something that was missing from the existing findings.

Some limitations have to be considered before drawing any relevant conclusions. Although there was an adequate sample size and ethical selection, if we narrow it down to each experimental group, a bigger sample would be preferable with a mixture of more settings and cultural backgrounds. However, it has to be acknowledged, there was a careful research design, with random sampling selection, experimental and control groups and substantial support to the practitioners to facilitate the implementation of the PLA. In addition to this, there was a mixed method approach with qualitative and quantitative analysis to examine holistically the outcome of the intervention.

Therefore, considering the above arguments, it can be argued that there is an added value in the research field through the findings of this study. These findings are useful to early childhood practitioners as a pioneering approach to teaching and as a motivating factor to researchers to implement this research design in further European and non-European countries all over the world.

\section{References}

Baroody, A.E. and Diamond, K.E. 2013. "Measures of Preschool Children's Interest and Engagement in Literacy Activities: Examining Gender Differences and Constructing Dimensions." Early Childhood Research Quarterly, 28:291-301.

Burdette, P., Franklin, T.O., East, B. and Mellard, D.F. 2015. Enrollment, Persistence, Progress, and Achievement. Practices and Challenges in Online Instruction for Students with Disabilities: State Education Agency Forum Proceedings Series (Report No.1). Kansas: University of Kansas. Retrieved $11^{\text {th }}$ February 2016, from $\quad$ http://centerononlinelearning.org/wpcontent/uploads/SEA_Topic_1_Summary_updated_July_2015.pdf

Cai, X. 2014. The Effects of Parents' Education Levels on Students'Persistence in College. MA Thesis. Georgetown University. Retrieved $11^{\text {th }}$ February 2016, from https://repository.library.georgetown.edu/handle/10822/709904

Catterall, J.S., Dumais, S.A. and Hampden-Thompson, G. 2012. The Arts and Achievement in atRisk Youth: Findings from Four Longitudinal Studies. Research Report 55. USA: National Endowment for the Arts. Retrieved 11 $1^{\text {th }}$ February 2015, 
from https://www.arts.gov/publications/arts-and-achievement-risk-youth-findings-fourlongitudinal-studies

David, T. and Goouch, K. 2001. "Early Literacy Teaching: The 'Third Way'.” Education 3-13, 29(2):19-24.

Eckhoff, A. 2013. "Conversational pedagogy: Exploring Interactions between a Teaching Artist and Young Learning during Visual Arts Experiences." Early Childhood Education Journal, 41:365-372.

Eisner, E. 1973-1974. “Examining Some Myths in Art Education.” Studies in Art Education, 15(3), 7-16.

Ferlazzo, L. 2011. “Involvement or Engagement?” Educational Leadership, 68(8):10-14.

Fleming, M. 2008. "Teaching Drama: Lessons from its Recent Development in the UK." Education and Theatre, 9:53-58.

Garvis, S. and Klopper, C. 2014. "Something Old, Something New, Something Borrowed but not Blue: The Educational Impact of the Arts." In Representation of Working in Arts Education: Stories of Learning and Teaching, edited by N. Lemon, S. Garvis and C. Klopper, 71-90. UK: Intellect.

Gerry, D., Unrau, A., Trainor, L.J. 2012. "Active Music Classes in Infancy Enhance Musical, Communicative and Social Development." Developmental Science, 15(3):398-407.

Giallo, R., Treyvaud, K., Cooklin, A. and Wade, C. 2013. "Mothers' and Fathers' Involvement in Home Activities with their Children: Psychosocial Factors and the Role of Parental SelfEfficacy." Early Child Development and Care, 183(3-4):343-359.

Hanley, G., P., Tiger, J., H., Ingvarsson, E., T. and Cammilleri, A., P. 2009. "Influencing Preschoolers' Free-Play Activity Preferences: An Evaluation of Satiation and Embedded Reinforcement." Journal of Applied Behavior Analysis, 42(1):33-41

Isenberg, J. and Jalongo, M.R. 2014. Creative Thinking and Arts-Based Learning: Preschool Through Fourth Grade. (6 ${ }^{\text {th }}$ Ed.). Virginia: Pearson.

Ishii-Kuntz, M. 2013. "Work Environment and Japanese Fathers' Involvement in China Care." Journal of Family Issues, 34(2):252-271.

Laevers, F. 1994. The Leuven Involvement Scale for Young Children LIS-YC Manual (Experiential Education Series 1). Leuven: Centre for Experiential Education. 
Leavy, P. 2015. Method Meets Art: Arts-Based Research Practice. $2^{\text {nd }}$ ed. London: The Guilford Press.

Loerts, T. and Heydon, R. 2017. "Multimodal Literacy Learning Opportunities within a Grade Six Classroom Literacy Curriculum: Constraints and Enablers." Education 3-13, 45(4):490503.

Maniaci, K., and Olcott, K.C. 2010. "Still Building That Idea: Preservice Art Educators' Perspectives on Integrating Literacy across the Curriculum." International Journal of Education and the Arts, 11(4).

Matthews, M. 2008. "How Can we Create the Conditions for Students' Freedom of Speech within Studies in Art?" The International Journal of Art and Design Education, 27(2):133-143.

Nichols, A.I. 2015. Examining the Role of Active Student Engagement in High School Art Course. $\mathrm{PhD}$ Thesis. Walden University. Retrieved 12 ${ }^{\text {th }}$ February 2015, from http://scholarworks.waldenu.edu/dissertations/187/

Phelps, R., Tuyet-Nhung, H.T., Graham, A. and Geeves, R. 2012. "But how do we Learn? Talking to Vietnamese Children about how they Learn in and out of School." International Journal of Educational Research, 53:289-302.

Ridley, S.M., McWilliam, R.A. and Oates, C.S. 2010. "Observed Engagement as an Indicator of Child Care Program Quality." Early Education and Development, 11(2):133-146.

Rydzik, A., Pritchard, A., Morgan, N. and Sedgley, D. 2013. "The Potential of Arts-Based Transformative Research." Annals of Tourism Research, 40:283-305.

Siraj-Blatchford, I., Sylva, K., Muttock, S. Gilden, R. and Bell, D. 2002. Researching Effective Pedagogy in the Early Years. (Research report 365). Norwich: Department of Education and Skills.

Siraj-Blatchford, I., Taggart, B., Sylva, K., Sammons, P. and Melhuish, E. 2008. "Towards the Transformation of Practice in Early Childhood Education: The Effective Provision of Preschool Education (EPPE) Project." Cambridge Journal of Education, 38(1):23-36.

Tekin, A.K. 2016. "Parental Perceptions of Life Context Variables for Involvement in their Young Children's Education." Education 3-13, 44(3):353-366.

Theodotou, E. 2015. “Can We Play Again with Picasso Miss? The Effects of the Arts in Children's Involvement During Literacy Activities in the Early Years Settings: A Case Study in the Greek Context." The 3rd International Academic Conference on Social Sciences. (pp.16- 
27). Georgia: The International Institute for Academic Development. ISBN 978-9941-07410-3.

Theodotou, E. 2017a. "Literacy as a Social Practice in the Early Years and the Effects of the Arts: A Case Study." International Journal of Early Years Education, 25(2):143-155. DOI: 10.1080/09669760.2017.1291332.

Theodotou, E. 2017b. "Examining Literacy Development Holistically Using the Play and Learn through the Arts (PLA) Programme: A Case Study." Early Child Development and Care. DOI: $10.1080 / 03004430.2017 .1326914$

Theodotou, E. 2017c. "Supporting Personal and Social Development through Child-Led Arts Projects in the Early Years Settings." Early Child Development and Care. DOI: $10.1080 / 03004430.2017 .1418739$

Tonc, A. 2002. Developing Skills of NGOS: Presentation and Communication. Hungary: The Regional Environment Center for Central and Easter Europe.

Tymms, P., Jones, P., Albone, S. and Henderson, B. 2009. "The First Seven Years at School." Educational Assessment, Evaluation and Accountability, 21(1):67-80.

Vasudevan, L. 2014. "A Picture Can do Things Words Can't: Transforming Representations in Literacy Research." In Handbook of research on teaching literacy through the communicative and visual arts, edited by J. Flood, S.B. Heath and D. Lapp, 187-194. Vol. II. London: Routledge.

Wilder, S. 2016. "Parental Involvement in Mathematics: Giving Parents a Voice." Education 313, 45(1):104-121.

Wray, D. and Medwell, J. 2006. "Pupil's Perspectives on Literacy Teaching." Education 3-13, 34(3):201-210.

Wright, S. 2007. “Graphic-Narrative Play: Young Children's Authoring through Drawing and Telling." International Journal of Education and the Arts, 8(8).

Yu, J.L.W. and Garces-Bacsal, R.M. \& Wright, S.K. 2017. "Young Children's Responses to Artwork: The Eye, the Mind, and the Body. International Journal of Education \& the Arts, 18(30). 